\title{
Evolutionary Game of Technology Innovation Investment in Supply Chain Enterprises with Government Subsidy Mechanism
}

\author{
Chenjun Zhang \\ School of Business Administration \\ Hohai University \\ Changzhou, China 213022
}

\author{
Junwei Tu \\ School of business \\ Hohai University \\ Nanjing, China 211100
}

\begin{abstract}
Under the background of the government strongly supports the enterprise's technology innovation, in view of the "free rider" problem of the supplier and the manufacturer in the supply chain enterprises in the technical innovation investment behavior. Frist, the payoff matrices is build when the supplier and the manufacturer adopting different strategies under the government subsidy mechanism. Then evolutionary stable strategies of technology innovation investment are analyzed by evolutionary game model. The results show that when the input-output ratios of the supplier and the manufacturer in different rage, technology innovation investment strategies of both parties will appear different evolutionarily stable equilibrium. At the same time, whether the government takes into account the positive externalities of technology innovation investment in the supply chain enterprises or not, the best subsidy for the technological innovation investment which makes the supplier and the manufacturer's evolutionary equilibrium will appear the state of technology innovation investment is calculated out. And under the best subsidy mechanism which not consider positive externalities the supplier and the manufacturer's evolutionary equilibrium will not appear the state of technology innovation investment.
\end{abstract}

Keywords-supply chain enterprises; technology innovation investment; government subsidy mechanism; evolutionary game

\section{INTRODUCTION}

With the intensification of market competition, the competition among enterprises has changed into the competition among supply chains [1]. The technological innovation of enterprises would not only strengthen the core competency of enterprises, but also benefit whole supply chain enterprises. However, a single enterprise in the supply chain tends to choose the most advantageous strategy to maximize its own profit, and there may be a "free rider" behavior. To motivate enterprises to carry out technological innovation, in addition to providing financial, tax and other preferential policies, the government will also adopt the method of financial subsidies [2]. Therefore, it is necessary to study the influential factors of the "free rider" behavior strategy in the supply chain, and design a reasonable subsidy mechanism to promote the choice of technology innovation investment strategy for the upstream and downstream enterprises in the supply chain.

At present, many scholars have applied the method of game theory and economics to study the technological innovation behavior of enterprises. From the perspective of the object investigated, the existing research paper can be classified into three categories. The first kind of research studies the technological innovation strategy between enterprises. For example: Dai Yuanyuan and others made an evolutionary game analysis on the choice of technological innovation mode of the enterprise and evolve to the "ideal state" through parameter adjustment; Su Xianna [4] and Yang Li [5] obtain the influencing factors which influence cooperative strategy choices through the evolutionary game analysis of the technology innovation cooperation strategy choices between enterprises; And scholars from abroad like Bayona[6], Okamuro[7], Amir[8], Kalaignanam[9], etc. have studied the cooperation of technology innovation among enterprises from different perspectives. The second kind of research studies the option of technology innovation strategy and coordination mechanism. Ji Guojun and others [10] differentiate the large enterprises and small- medium-sized enterprises in the industrial cluster, and analyze respectively the strategic option of independent innovation and the external imitation based on game theory. Huang Weidong [11], Cai Qiuhua [12], Zuo Zhiping [13], Wang Lili [1] and others have researched the cooperation strategy in the same supply chain and cross supply chain. Sun Xuelian and others [14] proposed a quantity discount contract to achieve the coordination between the manufacturer and the retailer in the condition of stochastic demand. The third kind of research is aimed at enterprises and government, mainly empirically analyzing the effect and influence of government subsidy and tax on enterprises' technological innovation activities. For example: Liu Xiaoyuan and other people [2] have studied the influence of local government subsidy and the tax incentive for the enterprise innovation.

The above documents have reflected the research of the enterprise's technological innovation from different perspective and important research results is obtained. While the behavioral research on the technology innovation strategy of supply chain enterprises mainly focuses on the 
game analysis of technology innovation cooperative and non-cooperative strategy option among supply chain enterprises, but ignoring the external positive effect of the enterprises' technology innovation investment. The research of Wang Lili [1] shows that, when there is one and only one investment on the technology innovation either from the manufacturer or suppliers, the benefit of the others who haven't invented on the technology innovation will increase. It theoretically demonstrates that the supply chain enterprise's technology innovation investment has external positive effect. The existence of external positive effect gives the supply chain enterprise a chance of "hitchhiking", which will affect their decision-making and it leads to behavior change of supply chain enterprise. Moreover, as of now, the game analysis of the technological innovation behavior of the supply chain enterprises has not considered the influence of the government subsidy. Based on above, this paper establishes the evolutionary game model of the supplier's and manufacturer's technology innovation investment under the precondition of government subsidy, analyzes the influencing factors of the choice behavior strategy, and probes into the optimal subsidy strength to motivate both the supplier and the manufacturer to choose the technology innovation investment strategy.

\section{MODEL ESTABLISHMENT}

This paper considers the two-stage supply chain, which is composed of upstream supplier and downstream manufacturers. The main game object of technological innovation investment is selected from the group of supplier and manufacturer randomly. The decision-making behavior of supplier and manufacturer is based on bounded rationality, that's to say, it achieves evolutionary stability in the process of continuous improvement and adjustment of strategy. The specific hypotheses are as follows:

- The strategic space of both the supplier (S) and manufacturer (M) is the technical innovation investment and non-technical innovation investment, which are denoted as D and $\mathrm{N}$.

- If both the supplier and the manufacturer don't carry out technical innovation investment, then, the production cost of the two parties won't decline regardless of the demand change led by uncertain factors beyond the supplier and manufacturer. At this point, the supplier and the manufacturer will receive earnings of RS, RM. And the RM > $0, \mathrm{RS}>0$.
- When the supplier and manufacturer are simultaneously engaged in the innovation investment, the profit of the supplier and the manufacturer is $(1+$ alpha 0$)$ RS-CS + IS and ( $1+$ beta 0$)$ RM -CM + IM. Alpha 0 and beta 0 is the profit increasing proportion of supplier and manufacturer when they invest in technological innovation respectively, and CS and $\mathrm{CM}$ is the cost of their technological innovation input respectively. IS and IM respectively represents government subsidies to supplier and manufacturer for technological innovation, including cash subsidies and tax, fiscal and financial incentives.

- When only the supplier is engaged in the technological innovation investment, it is assumed that the profit of the supplier is $(1+$ alpha 1$) \mathrm{RS}-\mathrm{CS}$ $+\mathrm{IS}$, the alpha 1 (alpha $0>$ Alpha $1>0$ ) is the proportion of the increase in the revenue of the supplier's technology innovation input; Manufacturers' revenue is VM, and the price of purchasing raw materials for manufacturer decreases correspondingly, the cost is relatively lower. Therefore, the manufacturer's income will also increase to a certain extent, namely, VM> RM.

- If only the manufacturer adopts the technology innovation input behavior strategy, the earnings of the supplier and the manufacturer are respectively VS and $(1+$ beta 1$) \mathrm{RM}-\mathrm{CM}+\mathrm{IM})$. And VS $>\mathrm{RS}$. This is because when manufacturer carries out technical innovation investment, relatively the product cost decreases, demand will increase, and the supply which supplier needs to provide increases correspondingly. In the case of constant input, income will increase as supply increases; Beta 1 represents the increase rate of the manufacturer's technological innovation input (beta $0>$ Beta $1>0$ ).

- In the supplier group, the proportion of "innovation technology input" and "non-technical innovation input" behavior strategy IS respectively $\mathrm{x}$ and 1-x, and $0<=X<=1$. At the same time, it is assumed that the proportion of "innovation technology input" and "non-technical innovation input" strategy in the manufacturer group is respectively y and $1-\mathrm{y}$, and 0 $<=\mathrm{y}<=1$.

Based on the above assumptions, the income matrix of supplier and manufacturer is established, as shown in the "Table I".

TABLE I. The Income Matrix OF Single MANufacture AND Single SuPPliER

\begin{tabular}{lll}
\hline \multirow{2}{*}{ Supplier (S) } & \multicolumn{2}{c}{ Manufacturer (D) } \\
\cline { 2 - 3 } & \multicolumn{1}{c}{ innovation technology input (D) } & \multicolumn{1}{c}{ non-technical innovation input (N) } \\
\hline innovation technology input $(\mathrm{D})$ & $((1+\alpha 0) \mathrm{RS}-\mathrm{CS}+\mathrm{IS},(1+\beta 0) \mathrm{RM}-\mathrm{CM}+\mathrm{IM})$ & $((1+\alpha 1) \mathrm{RS}-\mathrm{CS}+\mathrm{IS}), \mathrm{VM})$ \\
non-technical innovation input $(\mathrm{N})$ & $(\mathrm{VS},(1+\beta 1) \mathrm{RM}-\mathrm{CM}+\mathrm{IM})$ & $(\mathrm{RS}, \mathrm{RM})$ \\
\hline
\end{tabular}

\section{SOlUtion of Evolutionary Game Model}

\section{A. Equilibrium Point of the Evolution Process}

According to the above game model, we can obtain the expected income of the manufacturer using the technology innovation input strategy and non-technical innovation input strategy: Usd, Usn, and the average expected income Us, is respectively: 


$$
\left\{\begin{array}{l}
U_{S D}=y\left[\left(1+\alpha_{0}\right) R_{S}-C_{S}+I_{M}\right]+(1-y)\left[\left(1+\alpha_{1}\right) R_{S}-C_{S}+I_{M}\right] \\
U_{S N}=y V_{S}+(1-y) R_{S} \\
\bar{U}_{S}=x U_{S D}+(1-x) U_{S N}
\end{array}\right.
$$

In the same way, we can obtain the expected income of the manufacturer using the technology innovation input strategy and non-technical innovation input strategy, the

$$
\left\{\begin{array}{l}
U_{M D}=x\left[\left(1+\beta_{0}\right) R_{M}-C_{M}+I_{M}\right]+(1-x)\left[\left(1+\beta_{1}\right) R_{M}-C_{M}+I_{M}\right] \\
U_{M N}=x V_{M}+(1-x) R_{M} \\
\bar{U}_{M}=y U_{M D}+(1-y) U_{M N}
\end{array}\right.
$$

According to (1) and (2), the copy dynamic equations of the supplier and manufacturer can be obtained as follows:

$$
\begin{aligned}
& F(x)=\frac{d x}{d t}=x\left(U_{S D}-\bar{U}_{S}\right)=x(1-x)\left\{\alpha_{1} R_{S}-C_{S}+I_{S}-y\left[V_{S}-\left(\alpha_{0}-\alpha_{1}+1\right) R_{S}\right]\right\} \\
& G(y)=\frac{d y}{d t}=y\left(U_{M D}-\bar{U}_{M}\right)=y(1-y)\left\{\beta_{1} R_{M}-C_{M}+I_{M}-x\left[V_{M}-\left(\beta_{0}-\beta_{1}+1\right) R_{M}\right]\right\}
\end{aligned}
$$

Let $\mathrm{F}(\mathrm{x})=0, \mathrm{G}(\mathrm{y})=0$, obviously $(0,0),(0,1),(1,0)$, (1, 1) are the equilibrium points, and $F\left(\frac{\alpha_{1} R_{S}-C_{S}+I_{S}}{V_{S}-\left(\alpha_{0}-\alpha_{1}+1\right) R_{S}}\right)=0 \quad, \quad G\left(\frac{\beta_{1} R_{M}-C_{M}+I_{M}}{V_{M}-\left(\beta_{0}-\beta_{1}+1\right) R_{M}}\right)=0$ If $\frac{C_{S}-I_{S}}{R_{S}}<\alpha_{1}<a_{0}<\frac{C_{S}-I_{S}+V_{S}-R_{S}}{R_{S}} \quad, \quad \frac{C_{M}-I_{M}}{R_{M}}<\beta_{1}$ $<\beta_{0}<\frac{C_{M}-I_{M}+V_{M}-R_{M}}{R_{M}}$, then $\frac{\beta_{1} R_{M}-C_{M}+I_{M}}{V_{M}-\left(\beta_{0}-\beta_{1}+1\right) R_{M}} \in(0,1)$, $\frac{\alpha_{1} R_{S}-C_{S}+I_{S}}{V_{S}-\left(\alpha_{0}-\alpha_{1}+1\right) R_{S}} \in(0,1)$. Therefore, $\left(\frac{\alpha_{1} R_{S}-C_{S}+I_{S}}{V_{S}-\left(\alpha_{0}-\alpha_{1}+1\right) R_{S}}\right.$, $\frac{\beta_{1} R_{M}-C_{M}+I_{M}}{V_{M}-\left(\beta_{0}-\beta_{1}+1\right) R_{M}}$

$\left.\overline{V_{M}-\left(\beta_{0}-\beta_{1}+1\right) R_{M}}\right)$ is also the equilibrium point within that constraint.

\section{B. Analysis of Evolutionary Stability}

According to the analytical method proposed by Friedman [15], the stability analysis of evolutionary game equilibrium points can be obtained by the local stability of Jacobian matrix. Jacobian matrix is:

If the following conditions are met :

$$
J=\left|\begin{array}{cc}
\frac{\partial F(x)}{\partial x} & \frac{\partial F(x)}{\partial y} \\
\frac{\partial G(y)}{\partial x} & \frac{\partial G(y)}{\partial y}
\end{array}\right|=\left|\begin{array}{ll}
a_{11} & a_{12} \\
a_{21} & a_{22}
\end{array}\right|
$$

$\operatorname{tr} J=a_{11}+a_{22}<0$ (the trace of Jacobian matrix is less than 0) ;

$\operatorname{det} J=\left|\begin{array}{ll}a_{11} & a_{12} \\ a_{21} & a_{22}\end{array}\right|=a_{11} a_{22}-a_{12} a_{21}>0 \quad(($ Jacobian determinant is greater than 0 ).

The equilibrium point is asymptotically stable, and the strategy represented by the equilibrium point is the

\begin{tabular}{|c|c|c|}
\hline Equilibrium & trJ expression & detJ expression \\
\hline$(0,0)$ & $\left(\alpha_{1} R_{S}-C_{S}+I_{S}\right)_{+}\left(\beta_{1} R_{M}-C_{M}+I_{M}\right)$ & $\left(\alpha_{1} R_{S}-C_{S}+I_{S}\right)\left(\beta_{1} R_{M}-C_{M}+I_{M}\right)$ \\
\hline$(0,1)$ & $\left\{-C_{S}+I_{S}-\left[V_{S}-\left(\alpha_{0}+1\right) R_{S}\right]\right\}-\left(\beta_{1} R_{M}-C_{M}+I_{M}\right)$ & $\left\{-C_{S}+I_{S}-\left[V_{S}-\left(\alpha_{0}+1\right) R_{S}\right]\right\}\left[-\left(\beta_{1} R_{M}-C_{M}+I_{M}\right)\right]$ \\
\hline$(1,0)$ & $\begin{array}{l}\left\{-C_{M}+I_{M}-\left[V_{M}-\left(\beta_{0}+1\right) R_{M}\right]\right\} \\
+\left[-\left(\alpha_{1} R_{S}-C_{S}+I_{S}\right)\right]\end{array}$ & $\begin{array}{l}\left\{-C_{M}+I_{M}-\left[V_{M}-\left(\beta_{0}+1\right) R_{M}\right]\right\} \\
*\left[-\left(\alpha_{1} R_{S}-C_{S}+I_{S}\right)\right]\end{array}$ \\
\hline$(1,1)$ & $\begin{array}{l}-\left\{-C_{S}+I_{S}-\left[V_{S}-\left(\alpha_{0}+1\right) R_{S}\right]\right\}- \\
\left\{-C_{M}+I_{M}-\left[V_{M}-\left(\beta_{0}+1\right) R_{M}\right]\right\}\end{array}$ & $\begin{array}{l}\left\{-C_{S}+I_{S}-\left[V_{S}-\left(\alpha_{0}+1\right) R_{S}\right]\right\}^{*} \\
\left\{-C_{M}+I_{M}-\left[V_{M}-\left(\beta_{0}+1\right) R_{M}\right]\right\}\end{array}$ \\
\hline$\left(x^{*}, y^{*}\right)$ & 0 & $\begin{array}{l}\frac{C_{M}-I_{M}-\beta_{1} R_{M}}{V_{M}-\left(\beta_{0}-\beta_{1}+1\right) R_{M}} * \frac{\alpha_{1} R_{S}-C_{S}+I_{S}}{V_{S}-\left(\alpha_{0}-\alpha_{1}+1\right) R_{S}} *\left\{C_{s}\right. \\
\left.\left[V_{S}-\left(\alpha_{0}+1\right) R_{S}\right]-I_{S}\right\} *\left\{\left[V_{M}-\left(\beta_{0}+1\right) R_{M}\right]+C_{M}-I_{M}\right\}\end{array}$ \\
\hline
\end{tabular}
evolutionary stabilization strategy (ESS). The trace and determinant of Jacobian matrix at each equilibrium point are calculated as shown in "Table II".

TABLE II. EVOLUTION STABILITY OF EACH EQUILIBRIUM POINT

When alpha 0 , alpha 1 , beta 0 and beta 1 are in different ranges, different evolutionary stabilization strategies will appear. The following results can be obtained through analysis:
- When the supplier and the manufacturer's technology innovation investment income ratio $\alpha 0, \beta 0$ are both 
small, that is, $0<\alpha_{1}<\frac{C_{S}-I_{S}}{R_{S}} 、 0<\beta_{1}<\frac{C_{M}-I_{M}}{R_{M}}$, the increasing income ratio $\alpha_{1} R_{S}$ and $\beta_{1} R_{M}$ that supplier and manufacturer take technological innovation investment strategy alone are $\mathrm{C}_{\mathrm{S}}-\mathrm{I}_{\mathrm{S}}$ 、 $\mathrm{C}_{\mathrm{M}}-\mathrm{I}_{\mathrm{M}}$ smaller than the actual cost respectively. While

when

$$
\alpha_{1}<a_{0}<\frac{C_{S}+V_{S}-I_{S}-R_{S}}{R_{S}}
$$
and

$\beta_{1}<\beta_{0}<\frac{C_{M}+V_{M}-I_{M}-R_{M}}{R_{M}}$ that is to say, both of them adopt the technology innovation investment strategy, the earnings of both sides, $\left(\left(1+\alpha_{0}\right) R_{S}-C_{S}\right.$ $\left.+\mathrm{I}_{S}\right)$ and $\left(\left(1+\beta_{0}\right) \quad \mathrm{R}_{\mathrm{M}}-\mathrm{C}_{\mathrm{M}}+\mathrm{I}_{\mathrm{M}}\right)$, are both less than the income gained by the "free rider" $\mathrm{V}_{\mathrm{S}}$ and $\mathrm{V}_{\mathrm{M}}$. As shown in figure $1(\mathrm{a}),(1,1)$ is an unstable point, $(0,1)$ and $(1,0)$ are saddle points, and the evolutionary equilibrium point is $(0,0)$.

- When the manufacturer's technology innovation investment income ratio satisfies $\frac{C_{M}-I_{M}}{R_{M}}<\beta_{1}<\beta_{0}<\frac{C_{M}+V_{M}-I_{M}-R_{M}}{R_{M}}$ namely, the increasing income of technological innovation input done by manufacturer is greater than the cost. If the yield ratio of the supplier meets $0<\alpha_{1}<\frac{C_{S}-I_{S}}{R_{S}}$ and $\alpha_{1}<a_{0}<\frac{C_{S}+V_{S}-I_{S}-R_{S}}{R_{S}}$, when the increasing income of technological innovation input done by supplier is less than the cost, and the joint technical innovation investment income is less than nontechnical innovation investment income, at this point, the supplier will not choose technology innovation invest strategy, manufacturer can't be the "free rider". As shown in figure $1(\mathrm{~b}),(0,1)$ is the equilibrium point, $(0,0)$ and $(1,1)$ are saddle points, $(1,0)$ is unstable point. Under this condition, the evolutionary stable strategy is that the supplier doesn't choose the technical innovation investment, manufacturer chooses the technology innovation investment.

- When the yield ratio of the manufacturer meets the conditions $\frac{C_{S}-I_{S}}{R_{S}}<\alpha_{1}<a_{0}<\frac{C_{S}+V_{S}-I_{S}-R_{S}}{R_{S}}$, the yield ratio of the supplier is satisfied , $0<\beta_{1}<\frac{C_{M}-I_{M}}{R_{M}}$ and $\beta_{1}<\beta_{0}<\frac{C_{M}+V_{M}-I_{M}-R_{M}}{R_{M}}$. And the increasing income of technological innovation input done by manufacturer is less than the investment cost. The increasing income of technological innovation input done by supplier is greater than the cost. While the income when both of them do the technological innovation input strategy at the same time is less than the profit can be obtained by the hitchhike. As shown in figure $1(\mathrm{c}),(0,1)$ is unstable point, $(0,0)$ and $(1,1)$ are saddle points, $(1$, $0)$ is evolutionary equilibrium. The evolutionary equilibrium strategy is that the supplier carries out the technology innovation investment and manufacturers take non-technology innovation investment strategy.

- When $\frac{C_{S}-I_{S}}{R_{S}}<\alpha_{1}<a_{0}<\frac{C_{S}+V_{S}-I_{S}-R_{S}}{R_{S}} \quad$ and $\frac{C_{M}-I_{M}}{R_{M}}<\beta_{1}<\beta_{0}<\frac{C_{M}+V_{M}-I_{M}-R_{M}}{R_{M}}$, the increasing income of technical innovation investment carried by supplier and manufacturer is greater than the cost, and the common technical innovation investment returns are the revenues that are smaller than the "free-rider" as shown in figure $1(\mathrm{~d})$. At this point, the $(0,0)$ and $(1,1)$ are unstable points, $(\mathrm{x} * \mathrm{y} *)$ is a saddle point, and there are two equilibrium points, $(0,1)$ and $(1,0)$. When earnings ratio satisfies the condition, the chamber of supplier and the manufacturer will choose to do technology innovation investment, the other will choose non-technical innovation investment, but the specific evolution path and evolutionary equilibrium are associated with the initial condition and the payoff matrix of game. The broken line which is the border of two states consisted of a saddle point with two unstable points. Regional I (below the line), evolutionary equilibrium is $(1,0)$. While in the regional II (above the line), the equilibrium converges to $(0,1)$.

- When $\alpha_{0}>a_{1}>\frac{C_{S}+V_{S}-I_{S}-R_{S}}{R_{S}} \quad$ and $\beta_{0}>\beta_{1}>\frac{C_{M}+V_{M}-I_{M}-R_{M}}{R_{M}}$, that is, the benefits of technological innovation of both supplier and manufacturer are greater than that of the other party does the technology innovation investment while the technology innovation strategy is not carried out by itself. At this point, the equilibrium strategy is $(1,1)$, and both sides will choose to invest in technological innovation. $(0,1)$ and $(1,0)$ are unstable points. $(0,0)$ is a saddle point, as shown in figure 1 (e).

\section{THE GOVERNMENT'S OPTIMAL STRENGTH OF SUBSIDY}

\section{A. The Optimal Strength of Subsidy when the Government does not Consider External Positive Effects}

When the government provide subsidies, without considering the external positive effect between supply chain enterprises, namely manufacturer carries on technical innovation investment, while supplier chooses non-technical innovation investment, the supplier's profit is still the RS, likewise, when supplier chooses innovation input while manufacturer chooses non-technical innovation investment, the income for manufacturer is still the RM. When other assumptions are unchanged, the payoff matrix is shown in "Table III". 
TABLE III. REVENUE MATRIX IN GOVERnMENT's PERSPECTIVE

\begin{tabular}{lll}
\hline \multirow{2}{*}{ Supplier (S) } & \multicolumn{2}{c}{ Manufacturer (M) } \\
\cline { 2 - 3 } \multicolumn{1}{c}{ Technical innovation input (D) } & \multicolumn{1}{c}{ Non-Technical innovation input (N) } \\
\hline Technical innovation input (D) & $((1+\alpha 0)$ RS - CS +IS, $(1+\beta 0) R M-C M+I M)$ & $((1+\alpha 1)$ RS $-\mathrm{CS}+\mathrm{IS}), \mathrm{RM})$ \\
Non-Technical innovation input $(\mathrm{N})$ & $(\mathrm{RS},(1+\beta 0) \mathrm{RM}-\mathrm{CM}+\mathrm{IM})$ & $(\mathrm{RS}, \mathrm{RM})$
\end{tabular}

The replication dynamic equation of suppliers and manufacturers respectively is:

(5)

$$
F^{1}(x)=x(1-x)\left[\alpha_{1} R_{S}-C_{S}+I_{S}-y\left(\alpha_{1}-\alpha_{0}\right) R_{S}\right]
$$

$$
G^{1}(y)=y(1-y)\left[\beta_{1} R_{M}-C_{M}+I_{M}-x\left(\beta_{1}-\beta_{0}\right) R_{M}\right]
$$

To facilitate analysis, let $x^{*}=\frac{\beta_{1} R_{M}-C_{M}+I_{M}}{\left(\beta_{1}-\beta_{0}\right) R_{M}}$, $y^{*}=\frac{\alpha_{1} R_{S}-C_{S}+I_{S}}{\left(\alpha_{1}-\alpha_{0}\right) R_{S}}$.

1) The equilibrium point in the evolution process: Let $\mathrm{F} 1(\mathrm{x})=0, \mathrm{G} 1(\mathrm{y})=0$, obviously $(0,0),(0,1),(1,0),(1,1)$ are its equilibrium points, and $\mathrm{F} 1\left(\mathrm{x}^{*}\right)=0, \mathrm{G} 1\left(\mathrm{y}^{*}\right)=0$. When $0<x^{*}<1,0<y^{*}<1,\left(x^{*}, y^{*}\right)$ is the equilibrium point of the evolutionary game. Because $\alpha 0>\alpha 1 、 \beta 0>\beta 1$, to be the equilibrium point of the evolutionary game, $\left(\mathrm{x}^{*}, \mathrm{y}^{*}\right)$ needs $\begin{array}{ll}\text { to meet } \beta_{1} R_{M}-C_{M}+I_{M} & \text { conditions: } \beta_{1} R_{M}-C_{M}+I_{M}<0 \\ \text { and } & \end{array}$

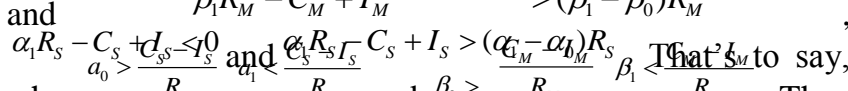
when ${ }_{0}>\frac{R_{S}}{R_{S}}, \frac{a_{1}}{R_{S}}$ and $\beta_{0}>\frac{R_{M}}{R_{M}}$. Then $\left(\mathrm{x}^{*}, \mathrm{y}^{*}\right)$ is the equilibrium point of the evolutionary game.

2) Stability analysis of evolutionary process: Likewise, we use the local stability of Jacobian matrix with differential equation to determine the stability of equilibrium point, and the trace and determinant of Jacobian matrix are shown in "Table IV".

\begin{tabular}{|c|c|c|}
\hline equilibrium & trJ expression & detJ expression \\
\hline$(0,0)$ & $\left(\alpha_{1} R_{S}-C_{S}+I_{S}\right)+\left(\beta_{1} R_{M}-C_{M}+I_{M}\right)$ & $\left(\alpha_{1} R_{S}-C_{S}+I_{S}\right)\left(\beta_{1} R_{M}-C_{M}+I_{M}\right)$ \\
\hline$(0,1)$ & {$\left[\alpha_{1} R_{S}-C_{S}+I_{S}-\left(\alpha_{1}-\alpha_{0}\right) R_{S}\right]-\left(\beta_{1} R_{M}-C_{M}+I_{M}\right)$} & $-\left(\beta_{1} R_{M}-C_{M}+I_{M}\right)\left[\alpha_{1} R_{S}-C_{S}+I_{S}-\left(\alpha_{1}-\alpha_{0}\right) R_{S}\right]$ \\
\hline$(1,0)$ & $-\left(\alpha_{1} R_{S}-C_{S}+I_{S}\right)+\left[\beta_{1} R_{M}-C_{M}+I_{M}-\left(\beta_{1}-\beta_{0}\right) R_{M}\right]$ & $-\left(\alpha_{1} R_{S}-C_{S}+I_{S}\right)\left[\beta_{1} R_{M}-C_{M}+I_{M}-\left(\beta_{1}-\beta_{0}\right) R_{M}\right]$ \\
\hline$(1,1)$ & $-\left(-C_{M}+I_{M}+\beta_{0} R_{M}\right)-\left(-C_{S}+I_{S}+\alpha_{0} R_{S}\right)$ & $\left(-C_{M}+I_{M}+\beta_{0} R_{M}\right)\left(-C_{S}+I_{S}+\alpha_{0} R_{S}\right)$ \\
\hline$\left(x^{*}, y^{*}\right)$ & 0 & $\begin{array}{l}\frac{\beta_{1} R_{M}-C_{M}+I_{M}}{\left(\beta_{1}-\beta_{0}\right) R_{M}} * \frac{\alpha_{1} R_{S}-C_{S}+I_{S}}{\left(\alpha_{1}-\alpha_{0}\right) R_{S}} \\
*\left(C_{M}-\beta_{0} R_{M}-I_{M}\right) *\left(C_{S}-\alpha_{0} R_{S}-I_{S}\right)\end{array}$ \\
\hline
\end{tabular}

TABLE IV. Evolution STABILITY OF EACH EQUILIBRIUM PoINT

In order to encourage supplier and the manufacturer of supply chain to make technical innovation investment strategy selection, the government should make( 1,1$)$ be the stable strategy of the game, and the government subsidy should meet the requirements: $I_{M}>C_{M}-\beta_{0} R_{M}, I_{S}>C_{S}-\alpha_{0} R_{S}$.

Proof: The necessary and sufficient condition for the equilibrium point $(1,1)$ to be the only stable strategy is $\operatorname{tr} \mathrm{J}<0$ and $\operatorname{det} \mathrm{J}>0$. As shown in table 4, $\quad-\left(-C_{M}+I_{M}+\beta_{0} R_{M}\right)-\left(-C_{S}+I_{S}+\alpha_{0} R_{S}\right)<0 \quad$ and $\left(-C_{M}+I_{M}+\beta_{0} R_{M}\right)\left(-C_{S}+I_{S}+\alpha_{0} R_{S}\right)>0$. Therefore, to satisfy $\alpha_{0} R_{S}-C_{S}+I_{S}>0$ and $\beta_{0} R_{M}-C_{M}+I_{M}>0$, we can obtain the necessary and sufficient condition $I_{M}>C_{M}-\beta_{0} R_{M}, I_{S}>C_{S}-\alpha_{0} R_{S}$

3) The analysis of incentive effect which is generated by the government not considering external effect subsidies: Government regarded as a rational decision-makers, often aims at obtaining the best effect of decision-making with minimum cost. For the government, was it not thinking for the external positive effect between supply chain enterprises, the extreme minimum value of government subsidies for $\operatorname{supplier}_{I_{S}}=C_{S}-\alpha_{0} R_{S}$ manufacturer is $I_{M}=C_{M}-\beta_{0} R_{M}$ 、

However, the profits of the upstream and downstream enterprises of the supply chain will increase when the technological innovation is carried out by a certain enterprise in the supply chain [1], that is, the external positive effect of supply chain enterprises exists objectively. Under the subsidy, it is obvious that:

$$
a_{0}<\frac{C_{S}-I_{S}+V_{S}-R_{S}}{R_{S}}, \beta_{0}<\frac{C_{M}-\mathrm{I}_{M}+V_{M}-R_{M}}{R_{M}}
$$


And because

$\alpha 0>\alpha 1$, $\beta 0>\beta 1$, $I_{M}<C_{M}-\beta_{1} R_{M}, I_{S}<C_{S}-\alpha_{0} R_{S}$, that is $0<\alpha_{1}<\frac{C_{S}-I_{S}}{R_{S}}$ $0<\beta_{1}<\frac{C_{M}-I_{M}}{R_{M}}$

According to the analysis of section 2.2, under the subsidy mechanism, the strategic equilibrium point of supplier and manufacturer is $(0,0)$, and neither party will invest in technological innovation. This also explains the reason that some industries are not vigorous in technological innovation under the government's innovation incentive strategy.

\section{B. Optimal Subsidy Strength for the External Effect Is Considered by the Government Subsidy}

When the government takes the existence of the external effect when the supply chain upstream and downstream take the technical innovation investment into account, the basis of decision making built on the return matrix shown in table 1 . To make both the supplier and the manufacturer carry on technology innovation investment, the necessary and sufficient condition is:

$$
I_{S}>V_{S}+C_{S}-R_{S}-\alpha_{0} R_{S} 、 I_{M}>V_{M}+C_{M}-R_{M}-\beta_{0} R_{M}
$$

Proof: the necessary condition for the equilibrium point $(1,1)$ to be the only dynamic equilibrium strategy is $\operatorname{tr} \mathrm{J}<0$ and $\operatorname{det} \mathrm{J}>0$. Known "Table II", $-\left\{-C_{S}+I_{S}-\left[V_{S}-\left(\alpha_{0}+1\right) R_{S}\right]\right\}-\left\{-C_{M}+I_{M}-\left[V_{M}-\left(\beta_{0}+1\right) R_{M}\right]\right\}<0$

$\left\{-C_{S}+I_{S}-\left[V_{S}-\left(\alpha_{0}+1\right) R_{S}\right]\right\} *\left\{-C_{M}+I_{M}\right.$

$\left.-\left[V_{M}-\left(\beta_{0}+1\right) R_{M}\right]\right\}>0$

therefore $\quad\left\{-C_{S}+I_{S}-\left[V_{S}-\left(\alpha_{0}+1\right) R_{S}\right]\right\}>0$ and

$\left\{-C_{M}+I_{M}-\left[V_{M}-\left(\beta_{0}+1\right) R_{M}\right]\right\}>0$. Therefore, the constraint conditions can be obtained respectively is $I_{S}>V_{S}+C_{S}-R_{S}-\alpha_{0} R_{S}, I_{M}>V_{M}+C_{M}-R_{M}-\beta_{0} R_{M}$.

\section{CONCLUSION}

This paper applies the evolutionary game theory to study the technological innovation investment strategy of suppliers and manufacturers under the government subsidy mechanism. The result shows that the strategy option is closely related to the return without technical innovation investment, the costs and contribution margin of technological innovation investment, and the quota limit of government subsidies; When the profit increase ratio of the technological innovation input of the two sides of the game is in the range of different interval, the evolution equilibrium will show four different stable states. In the end, this paper discusses the optimal subsidy limit if the government does not consider external positive effect between supply chain enterprises and their external positive effect. Without considering the external effect, the government's optimal subsidies cannot achieve the purpose of incenting the suppliers and manufacturers to do technological innovation investment.
Based on the government subsidy, this paper studies the technological innovation input strategy of enterprises in the supply chain, and it does not consider the influence of the supply chain's internal reward and punishment mechanism on the strategic option.

\section{REFERENCES}

[1] Wang L L, Chen G H. A game analysis on the technology innovation of chain-style industrial cluster[J]. Chinese Journal of Management Science, 2016, 24(1): 151-158.

[2] Liu X Y, lin S. Impact of local government behavior on technological innovation of start-up enterprises_dual perspectives of technological innovation resource allocation and innovation outputs[J]. R\&D Management, 2013, 25(5): 12-25.

[3] Dai Y Y, Mei Q. The technological innovation mode selection of Chinese new and high-tech enterprises based on evolutionary game[J]. Science Research Management, 2013, 34(1): 2-10.

[4] Su X N, Xie F J. An evolutionary game analysis on the strategy choice of cooperative innovation of firms[J]. R\&D Management, 2016, 28(1): 132-140.

[5] Yang L, Wei X P. Analysis on enterprises technological innovation behavior based on the evolution game[J].Science and Technology Management Research, 2010, 30(21): 18-21.

[6] Bayona C, Garia-Marco T, Huerta E. Firms' motivations for cooperative R\&D: An empirical analysis of Spanish firms [J] . Research Policy, 2001, 30 (8):1289-1307.

[7] Okamuro H. Determinants of successful R\&D cooperation in Japanese small businesses: The impact of organizational and contractual characteristics [J].Research Policy, 2007, 36 (10):1529 1544.

[8] Amir R, Jin J Y, Troege M. On additive spillovers and returns to scale in $\mathrm{R} \& \mathrm{D}[\mathrm{J}]$. International Journal of Industrial Organization, 2008, 26 (3):695 -703

[9] Kalaignanam K, Shankar V, Varadarajan R. Asymmetric new product development alliances: Win-Win or win-lose partnerships?[J] . Management Science, 2007, 53 (3 ) :357 -374.

[10] Ji G J, Wang, J. Evolutionary game analysis on technological innovation strategy choices of enterprises in industrial cluster[J]. Science \& Technology Progress and Policy, 2011, 28(20): 56-60.

[11] Huang W D, Xue, D Z, Gong, Y H. Differential decision model for collaboration technology innovation in low carbon supply chain[J]. Journal of Nanjing University of Posts and Telecommunications (Nature Science Edition), 2015, 35(4): 15-20.

[12] Cai Y H, Chen G H, Xiang X D. Analysis of technological innovation game model in firms of supply chain in clusters[J]. Chinese Journal of Management Science, 2010, 18(1): 72-77.

[13] Zuo Z P, Huang C H, Xia J. An evolutionary game analysis on innovation cooperative behavior based on two-dimensional cluster supply chain[J]. Journal of Indusrtial Technological Economics, 2013 , (1): 83-89.

[14] Sun X L, Deng F. Supply chain coordination of upstream technological innovation investment under stochastic demand[J]. Science and Technology Management Research, 2013, 33(4): 144147.

[15] Friedman D. Evolutionary game in economics [J]. Economy Erica, 1991, 59 (3): 637-666. 